\title{
LVII. A mercury-still for the rapid distillation of mercury in a vacuum
}

\section{Frederick J. Smith M.A.}

To cite this article: Frederick J. Smith M.A. (1890) LVII. A mercury-still for the rapid distillation of mercury in a vacuum , Philosophical Magazine Series 5, 29:181, 501-503, DOI: 10.1080/14786449008619974

To link to this article: http://dx.doi.org/10.1080/14786449008619974

曲 Published online: 08 May 2009.

Submit your article to this journal $\lceil\pi$

Џ Article views: 3

Q View related articles $\square$

Citing articles: 2 View citing articles $\square$ 
Mercury-still for the Rapid Distillation of Mercury.

\begin{tabular}{|c|c|c|c|}
\hline Solvent. & Dissolved substance. & Molec. depression. & Increase. \\
\hline $100 \mathrm{H}_{22} \mathrm{O}$ & 1 to $7 \mathrm{CaCl}_{2}$ & $2 \cdot 773$ to 6.9 & 150 per cent. \\
\hline $100\left(\mathrm{CaCl}_{2} 6 \mathrm{H}_{2} \mathrm{O}\right)$ & 1 to $800 \mathrm{H}_{2} \mathrm{O}^{2}$ & 0.003 to 0.099 & $3200^{\circ}$ \\
\hline $100 \mathrm{H}_{2} \mathrm{O}$ & 1 to $13 \mathrm{C}_{2} \mathscr{\mathrm { H }}_{6} \mathrm{O}$ & $1 \cdot 11$ to $1 \cdot 18$ & 6 \\
\hline
\end{tabular}

The increase in the case of alcohol is small, but still there is an increase, and not a decrease; while in the case of water in the hydrate of calcium chloride the increase is almost the greatest at present known.

\section{Irregularity of the Deviations with Weak Solutions.}

That the deviations from constancy are not regular, and are not even always in the same direction, will be seen on referring to the results with sulphuric acid dissolved in water (p.499); the depression in the freezing-point of the tetrahydrate, both by water and sulphuric acid, supplying two other instances of a similar character.

Since every fact which can be used to test whether the theory of osmotic pressure is a true explanation of the nature and behaviour of solutions, either fails to give any evidence in its favour, or else gives evidence directly opposed to it-evidence, often, of the strongest possible character-this theory can certainly not yet bo regarded as established.

LVII. A Mercury-still for the Rapid Distillation of Mercury in a Vacuum. By Frederick J. SMITH, M.A., Millard Lecturer in Mechanics and Physics, Trinity College, Oxford* WHEN mercury is distilled in a vacuum, in the usual apparatus, a large portion of it when vaporized, on reaching the internal domed surface of the bulb in which the operation is conducted, forms itself into minute spheres, which grow heavy and run down the inside of the bulb; and only a small quantity of the metal finds its way into the central tube, from which it is caught for use.

The advantage of the new form of vacuum mercury-still, of which I venture to give an account, is that all the mercury, which condenses in the head of the bulb, is prevented by its shape from returning to the mercury from which it has been separated by heat. This is not the case in the mercury-still of Weinhold, or Clark, or in those stills in which only the mercury which collects in the eduction-tube is caught, as in

* Communicated by the Author.

Phil. Mag. S. 5. Vol. 29. No. 181. June 1890. 2 Q 
the beautiful new form of apparatus, devised by Messrs. Dunstan and Dymond, for the purification of small quantities of mercury (suprà, p. 367). In the former of these instruments, "some portion of the mercury-vapour condenses on the surface of the bulb and then falls back to the mass of mercury from which it has just been separated. The mercury-still which is described in the following lines has been constructed with a view to obtain a more rapid yield of pure mercury than stills of this class have hitherto been capable of producing. The yield of mercury from the now form of still is about four times as great as that from one of the old pattern, the consumption of gas in each case being the same. The construction and method of using the still are as follows:- $\mathrm{B} \mathrm{K}$ is a bulb and tube about 34 inches long, supported on a stand not shown; the bulb has a ring-shaped channel, C C, round its upper end ; into this channel a piece of "Sprengel" tube, D, is fused. This is furnished with two

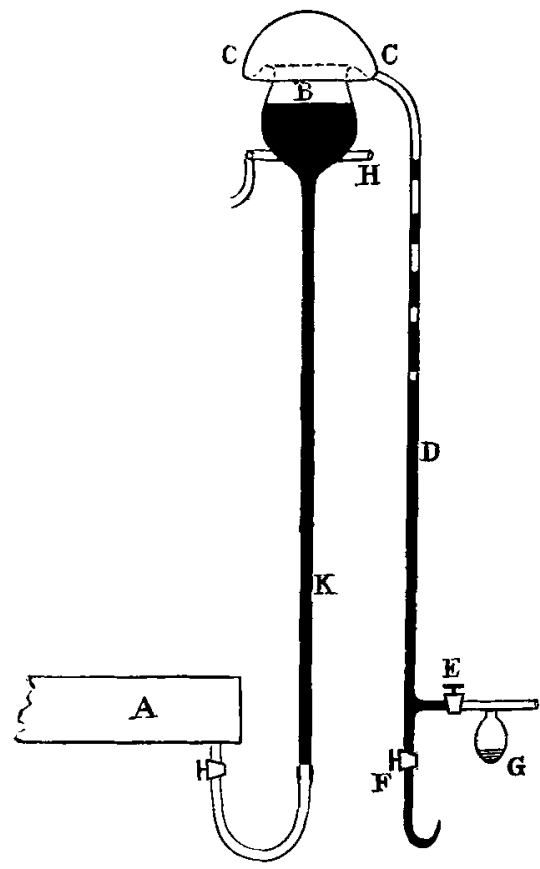

taps of glass, $\mathrm{E}$ and $\mathrm{F} ; \mathrm{E}$ is in connexion with a water-jet pump, $F$ is terminated with a piece of bent tube. $A$ is a cistern for holding the mercury which is to be distilled. $\mathrm{H}$ is a ring of gas-jets. 
The method of using the still is as follows:-The tap E is opened, $F$ is closed; a water-pump then exhausts the whole system, and the mercury to be acted on rises from the cistern $\mathrm{A}$. The cistern being large and shallow, only a slight change takes place in the height of the mercury in the bulb, when the level of the mercury in the cistern changes. While the pump is exhausting the ring of gas-jets is lit, and in about ten minutes, in the case of the still in our laboratory, the mercury fills the tube $\mathrm{D}$, any metal which comes over being caught in the bulb $G$. The tap $E$ is then closed and $F$ opened; the still then continues to work by virtue of the vacuum formed by its own mercury. It has been found necessary to place a gas-regulator on the pipe which supplies the jets, as the change of pressure in the gas-mains is considerable. An automatic arrangement, depending for its action upon the height of the mercury in the cistern, shuts off the gas when the surface of the mercury falls below a certain point. In using stills of this class the mercury before distillation should be carefully freed from moisture, as a minute quantity of water will often cause a fracture in the heated tube or bulb.

LVIII. On the Distribution of Flow in a Strained Elastic Solid. By Charles A. Carus-Wilson, B.A., A.M.I.C.E., Demonstrator in the Mechanical Laboratory at the Royal Indian Engineering College, Coopers Hill**

TF a metal bar of uniform section throughout its length be subjected to uniform'longitudinal stress, the elements of the bar will become distorted ; if the strain should exceed the limit of elasticity the distortion will be partly permanent.

In consequence of the straining of the elements, every element will experience a displacement relative to three fixed axes in the bar; say $o x$ parallel to the length of the bar, oy parallel to one side, and $o z$ parallel to a second side, both $o z$ and $o y$ being at right angles to $o x$ : such displacement is generally spoken of as "flow."

It is clear that if the metal be homogeneous, the stress uniform, and the section at right angles to the axis everywhere the same, an element will experience a displacement at right angles to the planes $x o z, y o z$ proportional to its distance from these planes; since such displacement depends on the straining of the elements between it and these planes. Hence a bar with its sides originally parallel to $o x$ will remain so

* Communicated by the Physical Society : read May 2, 1890. $2 \mathrm{Q} 2$ 